\title{
Insulin Action on Heart and Skeletal Muscle Glucose Uptake in Essential Hypertension
}

\author{
Pirjo Nuutila, * Maija Mäki, ${ }^{*}$ Hanna Laine, * M. Juhani Knuuti, ${ }^{5}$ Ulla Ruotsalainen," Matti Luotolahti, ${ }^{5}$ Merja Haaparanta," \\ Olof Solin, ' Antti Jula, ${ }^{* *}$ Veikko A. Koivisto, \# Liisa-Maria Voipio-Pulkki, ${ }^{\star}$ and Hannele Yki-Järvinen ${ }^{\text {ss }}$ \\ *Department of Medicine, ${ }^{\ddagger}$ Department of Clinical Physiology, ${ }^{8}$ Department of Nuclear Medicine, "Turku University Cyclotron/PET \\ Center, University of Turku, 'Accelerator Laboratory, Ảbo Akademi, FIN-20520 Turku, Finland, **The Rehabilitation Research Centre \\ of Social Insurance Institution, FIN-20720 Turku, ${ }^{\ddagger \ddagger}$ Second and ${ }^{85}$ Third Department of Medicine, University of Helsinki, \\ FIN-00190 Helsinki, Finland
}

\begin{abstract}
Essential hypertension is characterized by skeletal muscle insulin resistance but it is unknown whether insulin resistance also affects heart glucose uptake. We quantitated whole body (euglycemic insulin clamp) and heart and skeletal muscle (positron emission tomography and ${ }^{18} \mathrm{~F}$-fluoro-2deoxy-D-glucose) glucose uptake rates in 10 mild essential hypertensive (age $33 \pm 1 \mathrm{yr}$, body mass index $23.7 \pm 0.8 \mathrm{~kg} /$ $\mathrm{m}^{2}$, blood pressure $146 \pm 3 / 97 \pm 3 \mathrm{mmHg}, V_{2} \mathrm{o}_{\max } 37 \pm 3 \mathrm{ml} /$ kg per min) and 14 normal subjects $(29 \pm 2 \mathrm{yr}, 22.5 \pm 0.5$ $\mathrm{kg} / \mathrm{m}^{2}, 118 \pm 4 / 69 \pm 3 \mathrm{mmHg}, 43 \pm 2 \mathrm{ml} / \mathrm{kg}$ per $\left.\mathrm{min}\right)$. Left ventricular mass was similar in the hypertensive $(155 \pm 15$ g) and the normotensive ( $164 \pm 13 \mathrm{~g})$ subjects. In the hypertensives, both whole body ( $28 \pm 3$ vs $44 \pm 3 \mu \mathrm{mol} / \mathrm{kg}$ per min, $P<0.01)$ and femoral $(64 \pm 11$ vs $94 \pm 8 \mu \mathrm{mol} / \mathrm{kg}$ muscle per min, $P<0.05)$ glucose uptake rates were decreased compared to the controls. In contrast, heart glucose uptake was $33 \%$ increased in the hypertensives (939 \pm 51 vs $707 \pm 46$ $\mu \mathrm{mol} / \mathrm{kg}$ muscle per min, $P<0.005)$, and correlated with systolic blood pressure $(r=0.66, P<0.001)$ and the minute work index $(r=0.48, P<0.05)$. We conclude that insulinstimulated glucose uptake is decreased in skeletal muscle but increased in proportion to cardiac work in essential hypertension. The increase in heart glucose uptake in mild essential hypertensives with a normal left ventricular mass may reflect increased oxygen consumption and represent an early signal which precedes the development of left ventricular hypertrophy. (J. Clin. Invest. 1995. 96:1003-1009.) Key words: insulin resistance - hypertrophy • left ventricle • tomography
\end{abstract}

\section{Introduction}

Insulin resistance characterizes patients with essential hypertension (1-3). When glucose uptake is measured during insulin stimulation, the majority $(70-80 \%)$ of glucose is taken up by skeletal muscles in normal subjects (4) and patients with essen-

Address correspondence to Pirjo Nuutila, Department of Medicine, University of Turku, FIN-20520 Turku, Finland. Phone: 358-21-2611 611; FAX: 358-21-2612 030.

Received for publication 23 November 1994 and accepted in revised form 21 March 1995.

J. Clin. Invest.

(C) The American Society for Clinical Investigation, Inc.

0021-9738/95/08/1003/07 \$2.00

Volume 96, August 1995, 1003-1009 tial hypertension (5). Thus, whole body insulin resistance can be attributed to diminished glucose uptake by skeletal muscles in these patients (5). However, the heart rather than skeletal muscle is the organ ultimately adversely affected by hypertension. Physiological insulin concentrations increase glucose uptake in the heart in normal subjects by about eightfold under normoglycemic conditions $(6,7)$. It is unknown whether this action of insulin is altered in essential hypertension.

In rats, induction of cardiac hyperfunction by interventions such as aortic constriction (8) or atrial pacing (9), increases oxygen and energy consumption per unit mass of myocardium in proportion to the degree of hyperfunction. Aortic constriction also increases glucose uptake in the rat heart (8). In the latter study, the increase in glucose uptake was attributed to doubling of blood glucose concentrations due to the stress of aortic constriction, and an increase in plasma norepinephrine concentrations. In hearts of severely hypertensive fed rats, Yonekura et al. (10) found increased glucose uptake but in this study the concentration of circulating substrates and hormones was not determined. Long-term systemic hypertension induces left ventricular pressure and volume overload, and ultimately cardiac hypertrophy (11). Under such conditions, oxygen consumption is generally normal per unit mass of myocardium, although total heart oxygen consumption is increased (8). It is unclear, however, whether these data are pertinent for understanding the effect of hypertension on heart glucose metabolism in humans. The present study was therefore undertaken to determine, whether and how glucose utilization in the mildly hypertensive heart is altered during insulin stimulation. We also examined whether poor physical fitness is associated with insulin resistance in patients with mild essential hypertension. Heart and muscle glucose uptake rates were determined during insulin stimulation in essential hypertensives and normal subjects using positron emission tomography (PET) ${ }^{1}$ derived ${ }^{18} \mathrm{~F}$-fluoro-2deoxy-D-glucose $\left({ }^{18} \mathrm{FDG}\right)$ kinetics. Whole body insulin sensitivity was determined simultaneously but independent of the regional measurements using the euglycemic insulin clamp technique.

\section{Methods}

Subjects. The study group consisted of 10 ambulatory patients with untreated mild essential hypertension (Table I). The diagnosis was made when diastolic blood pressure equaled or exceeded $100 \mathrm{mmHg}$ on at least three occasions, with the patient in supine position. A complete medical workup was carried out to exclude secondary forms of hyperten-

1. Abbreviations used in this paper: ${ }^{18} \mathrm{FDG},{ }^{18} \mathrm{~F}$-fluoro-2-deoxy-D-glucose; PET, positron emission tomography. 
Table I. Subject Characteristics

\begin{tabular}{lccc}
\hline & Hypertensives & Controls & $P$ \\
\hline Age (yr) & $33 \pm 1$ & $29 \pm 2$ & $\mathrm{NS}$ \\
Male/Female & $4 / 6$ & $8 / 6$ & $\mathrm{NS}$ \\
Body mass index $\left(\mathrm{kg} / \mathrm{m}^{2}\right)$ & $23.7 \pm 0.8$ & $22.5 \pm 0.5$ & $\mathrm{NS}$ \\
Vo 2 max (ml/kg per min) & $37 \pm 3$ & $43 \pm 2$ & $\mathrm{NS}$ \\
Blood pressure & & & \\
$\quad$ systolic (mmHg) & $146 \pm 3$ & $118 \pm 4$ & $<0.001$ \\
$\quad$ diastolic (mmHg) & $97 \pm 3$ & $69 \pm 3$ & $<0.001$ \\
Heart rate $(1 / \mathrm{min})$ & $69 \pm 3$ & $65 \pm 2$ & $\mathrm{NS}$ \\
Rate-pressure product & & & \\
$\quad$ (mmHg/min) & $10120 \pm 458$ & $7608 \pm 433$ & $<0.001$ \\
Left ventricular mass $(\mathrm{g})$ & $155 \pm 15$ & $164 \pm 13$ & $\mathrm{NS}$ \\
Left ventricular mass index $\left(\mathrm{g} / \mathrm{m}^{2}\right)$ & $88 \pm 6$ & $87 \pm 6$ & $\mathrm{NS}$ \\
Ejection fraction & $64 \pm 1$ & $62 \pm 1$ & $\mathrm{NS}$ \\
Minute work per myocardial mass & & & \\
$\quad$ (mmHg $\times$ liter/min $\times \mathrm{g})$ & $5.4 \pm 0.5$ & $3.9 \pm 0.4$ & $<0.02$ \\
Minute work index $(\mathrm{mmHg} \times$ & & & \\
$\quad$ liter/min $\times$ m $\left.{ }^{2}\right)$ & $457 \pm 37$ & $338 \pm 39$ & $<0.05$ \\
\hline & & & \\
\hline
\end{tabular}

sion. Renal, liver, and endocrine function tests were normal, and none of the subjects had any signs or symptoms of ischemic heart disease or other disease. 14 normotensive healthy subjects matched for age, gender, and body mass index formed the control group (Table I). None of the normal subjects or hypertensives used any medications.

At least $3 \mathrm{~d}$ before the study, the subjects consumed a weightmaintaining diet containing at least $200 \mathrm{~g}$ of carbohydrate and avoided participation in any physical training. The nature, purpose, and potential risks of the study were explained to all subjects before they gave their voluntary consent to participate. The study was approved by the Ethical Committee of the Turku University Hospital, Turku, Finland.

Study design. In each subject whole body glucose uptake was measured using the euglycemic insulin clamp technique and regional (heart and femoral muscle) glucose uptake using PET and ${ }^{18}$ FDG. In addition, $\mathrm{Vo}_{2 \max }$ and left ventricular structure were determined using a standard incremental bicycle ergometer test and M-mode echocardiography, respectively. The study consisted of a 120-min hyperinsulinemic period (Fig. 1). Between 0 and $120 \mathrm{~min}$, whole body glucose uptake was measured under normoglycemic hyperinsulinemic conditions using the euglycemic insulin clamp technique. For measurement of heart and skeletal muscle glucose uptake, ${ }^{18}$ FDG was injected at $60 \mathrm{~min}$, and dynamic scanning was started (Fig. 1). Blood samples for the measurement of plasma glucose, serum insulin, FFA concentrations, and ${ }^{18}$ FDG radioactivity were taken as detailed below.

Whole body glucose uptake. Whole body glucose uptake was determined using the euglycemic insulin clamp technique (12). All studies were performed starting at 8:00 a.m. after a 10-12-h overnight fast. Two catheters were inserted, one in an antecubital vein for infusions of glucose and insulin and injection of ${ }^{18} \mathrm{FDG}$, and one in a heated $\left(70^{\circ} \mathrm{C}\right)$ hand vein for sampling of arterialized venous blood.

At 0 min, serum insulin was increased for 120 min using a primedcontinuous infusion of insulin (Actrapid; Novo Nordisk A/S, Copenhagen, Denmark). The rate of the continuous insulin infusion was $1 \mathrm{mU}$ $(6 \mathrm{pmol}) / \mathrm{kg}$ per min. Normoglycemia was maintained using a variable rate infusion of $20 \%$ glucose. The rate of the glucose infusion was adjusted according to the plasma glucose concentration, which was measured every $5 \mathrm{~min}$ from arterialized venous blood using the glucose oxidase method (13). Hepatic glucose production is completely suppressed under these conditions (14). The rate of whole body glucose uptake was calculated during the time of PET scanning (60-120 min). Blood samples were taken at 20-30-min intervals for measurement of serum insulin (15) and FFA (16) concentrations.

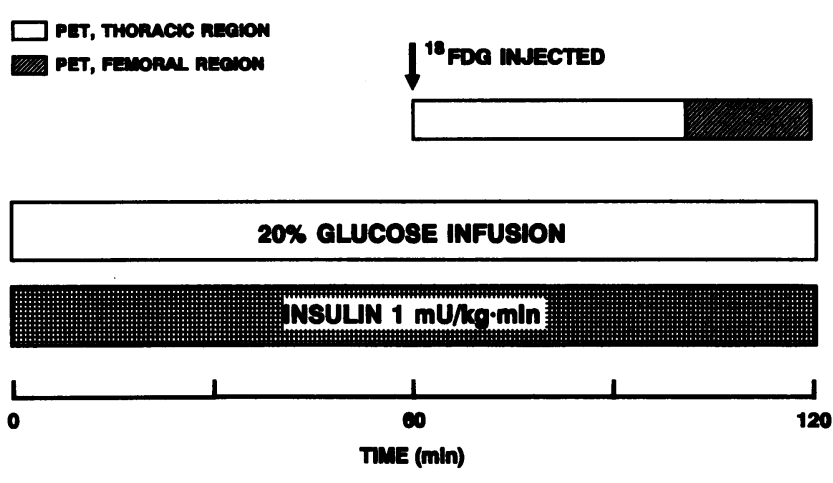

Figure 1. Design of the study. The arrow indicates the time of the ${ }^{18}$ FDG injection. After the injection, dynamic PET scanning of the thoracic and femoral regions was performed to quantitate regional glucose uptake rates. Whole body glucose uptake was measured using the euglycemic insulin clamp technique (insulin infusion rate $1 \mathrm{mU} / \mathrm{kg}$ per min).

Regional glucose uptake by heart and skeletal muscles. These measurements were performed using positron emission tomography as previously described (6). The method included the following procedures.

Preparation of ${ }^{18} \mathrm{FDG} .{ }^{18} \mathrm{FDG}$ was synthesized with an automatic apparatus essentially described by Hamacher et al. (17). The specific radioactivity at the end of the synthesis was $\sim 2 \mathrm{Ci} / \mu \mathrm{mol}$ and the radiochemical purity exceeded $98 \%$.

Image acquisition. A 15 slice ECAT 931/08-tomograph (Siemens/ CTI Corp., Knoxville, TN) was used. The device has a measured axial resolution of $6.7 \mathrm{~mm}$ and resolution of $6.5 \mathrm{~mm}$ in plane (18). The subject was positioned in the tomograph first with arms on sides so that the heart was within the gantry. Thereafter images were obtained from femoral regions. Before emission scanning, a transmission scan for correction of attenuation in the body was performed for 20-30 $\mathrm{min}$. In each plane $15-30 \times 10^{6}$ counts were obtained.

$1 \mathrm{~h}$ after starting the insulin infusion, $7-8 \mathrm{mCi}$ of ${ }^{18} \mathrm{FDG}$ was injected intravenously over $20 \mathrm{~s}$ (Fig. 1). Dynamic scanning of the thoracic region was started simultaneously and continued for $40 \mathrm{~min}(8 \times 15$ $2 \times 30,2 \times 120,1 \times 180,6 \times 300 \mathrm{~s})$. Thereafter, five dynamic scans of $180 \mathrm{~s}$ each were taken from the femoral region. Blood samples for measurement of plasma radioactivity was withdrawn once during each frame time to create the time activity curve.

Image processing. All data were corrected for deadtime, decay, and measured photon attenuation as previously described (6) and reconstructed into a $256 \times 256$ matrix. For determination of myocardial glucose uptake, elliptical regions of interest (ROIs) were placed on seven different segments of the myocardium (19). Myocardial time activity curves were corrected for partial volume and spillover effects (20). In the femoral muscle, we used posterior, anterolateral, and anteromedial muscular compartments of the femoral region (four slices in both legs). Their localization was verified by comparison with the position observed in the transmission images. An example of the corrected time activity curves in the plasma, heart, and femoral muscles is shown in Fig. 2. Trapping of ${ }^{18}$ FDG in the heart was more intense in hypertensive than the normal subjects, while ${ }^{18}$ FDG activity in the femoral muscles was higher in the control than in hypertensive subjects.

Calculation of regional glucose uptake. The three compartment model of ${ }^{18}$ FDG kinetics was used as previously described $(6,21)$. Plasma and tissue time activity curves were analyzed graphically to quantitate the fractional rate of tracer uptake and phosphorylation $K_{\mathrm{i}}$ (22). $K_{\mathrm{i}}$ is equal to $\left(k_{1} \times k_{3} / k_{2}+k_{3}\right)$, where $k_{1}$ is the transfer coefficient from vascular space into the tissue, $k_{2}$ is the initial clearance and efflux coefficient and $k_{3}$ is the phosphorylation rate constant. The Patlak analysis assumes that the rate of dephosphorylation $\left(k_{4}\right)$ is zero (22). As shown in reference 23 , at least in the heart $k_{4}$ will become important after $60 \mathrm{~min}$. In the present study, the measurements were done within $65 \mathrm{~min}$ from the injection. If in the graphical analysis the plot is linear, 

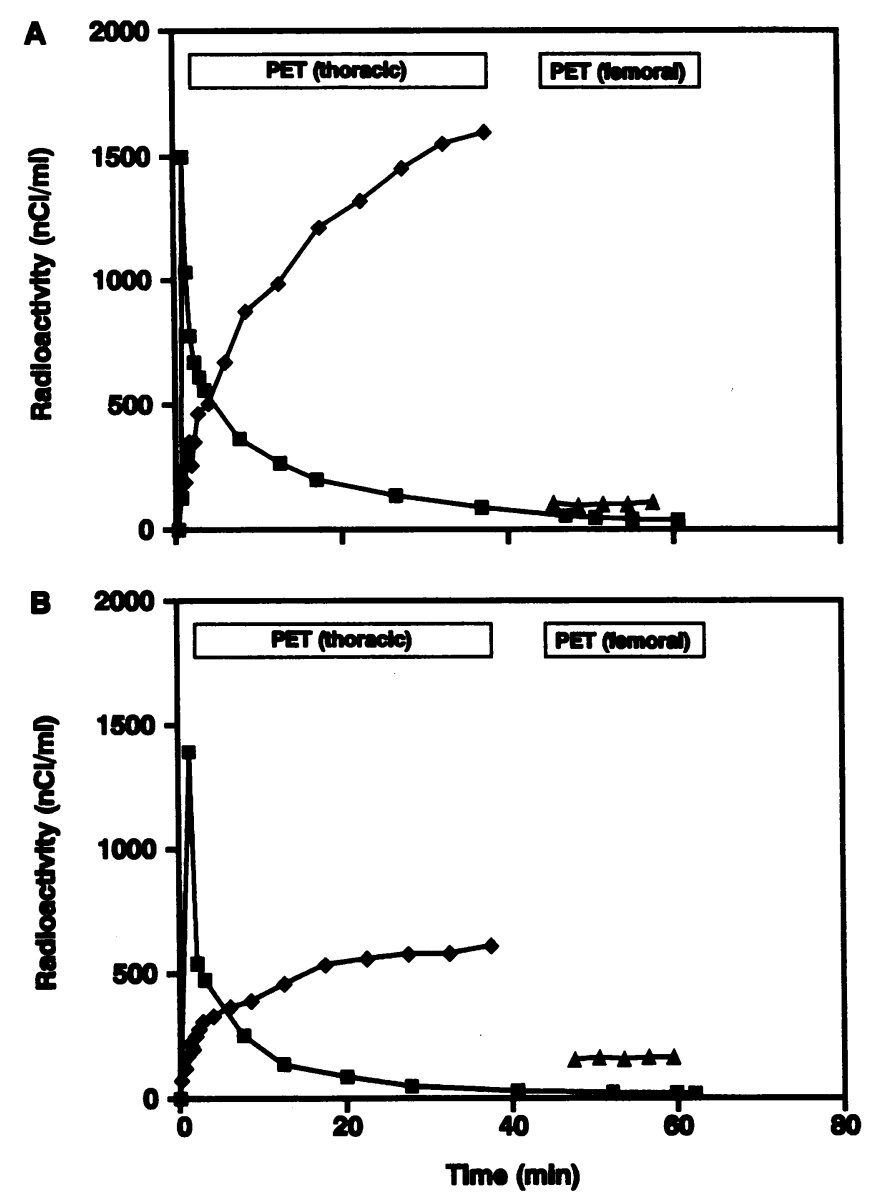

Figure 2. Example of corrected time activity curves for plasma ( $\boldsymbol{\nabla})$, myocardium $(\bullet)$, and femoral muscle $(\Delta)$ in a control subject $(A)$ and in a hypertensive subject $(B)$.

for some period, the underlying assumptions of the method are valid for that period (22). In this study, the fitted plasma time activity curve was used as the input function and a minimum of six time points were used to determine the slope by linear regression for the thoracic study and five points were used for the femoral study. The plots between the points were linear (for myocardium $r=0.96 \pm 0.03$; for skeletal muscle $r$ $=0.84 \pm 0.05$ ) and the residuals of the regression lines were stocastically scattered. Although the linear regression $r$ value was lower for skeletal muscle than for myocardium, the scanning period of $15 \mathrm{~min}$ was long enough since both $r$ values $(0.84 \pm 0.05$ vs $0.85 \pm 0.06$ for five [ $15 \mathrm{~min}$ ] vs four [12 min] points and $K_{i}$ values $(0.0176 \pm 0.0042$ vs $0.0177 \pm 0.0054)$ remained unchanged when only four points $(12 \mathrm{~min})$ were used to determine the slope.

The rate of glucose utilization is obtained by multiplying $K_{\mathrm{i}}$ by the plasma glucose concentration [Glc] $]_{p}$ divided by a lumped constant term (LC): $\left.\mathrm{rGU}=[\mathrm{Glc}]_{\mathrm{p}} / \mathrm{LC}\right) \times K_{\mathrm{i}}$. The lumped constant accounts for differences in the transport and phosphorylation rate of ${ }^{18} \mathrm{FDG}$ and glucose. Lumped constant values of 0.67 for the heart $(6,23,24)$ and 1.0 for the skeletal muscle $(6,25)$ were used as previously described.

Left ventricular structure. M-mode and two-dimensional echocardiography (Acuson 128XP/5; Acuson Inc., Mountain View, CA) were performed in the hypertensives and control subjects to determine enddiastolic and end-systolic left ventricular dimensions, and septal and posterior free wall thicknesses. Left ventricular mass was calculated according to the Penn convention (26). Minute work for the myocardium was calculated according to the equation: mean blood pressure $\times$ cardiac output (27). Minute work index was calculated by dividing minute work by body surface area, and minute work per mass by dividing minute work by left ventricular mass.

Maximal aerobic power $\left(\mathrm{Vo}_{2 \max }\right) \mathrm{Vo}_{2 \max }$ was determined in the study subjects using an electrically braked cycle ergometer (Ergoline $800 \mathrm{~S}$; Mijnhardt, Bunnik, Netherlands) with a continuous incremental protocol. Direct respiratory measurements were made using an automated system (Medikro 202; Medicro Oy, Kuopio, Finland). Subjects breathed through a Daniel's valve, with expired gases directed to a mixing chamber for paramagnetic $\mathrm{O}_{2}$ and infrared $\mathrm{CO}_{2}$ analysis (Datex Division; Instrumentarium Corp., Helsinki, Finland). Outputs from these instruments were directed to a computer for calculation of ventilation, $\mathrm{O}_{2}$ consumption $\left(\mathrm{VO}_{2}\right), \mathrm{CO}_{2}$ production $\left(\mathrm{VCO}_{2}\right)$, and respiratory exchange ratio $(R)$ every $30 \mathrm{~s}$. The $\mathrm{Vo}_{2 \max }$ test consisted of a short warm-up, after which the load was increased from $100 \mathrm{~W}$ by $30 \mathrm{~W}$ every 2 min until exhaustion. The criteria used to establish the $\mathrm{Vo}_{2 \max }$ were a plateau in $\mathrm{VO}_{2}$ with increasing exercise intensity and $\mathrm{R}>1.10$. Calibration against standard gases $\left(16 \% \mathrm{O}_{2}\right.$ and $\left.4 \% \mathrm{CO}_{2}\right)$, volume $(3,000 \mathrm{ml})$, room temperature, and barometric pressure was performed before and immediately after each test.

Statistical procedures. Statistical comparisons between hypertensive subjects and controls were performed using the unpaired $t$ test and correlations were calculated using Pearson's correlation coefficients. Analysis of covariance was used to study the influence of age and $\mathrm{Vo}_{2 \max }$ on glucose uptake rates between the two groups using the Systat statistical package (SYSTAT Inc., Evanston, IL). Data are expressed as means \pm SE.

\section{Results}

Glucose, insulin, and FFA concentrations. Plasma glucose concentrations were similar in the hypertensive and control subjects both in the basal state $(5.2 \pm 0.1$ vs $5.3 \pm 0.1 \mathrm{mmol} / \mathrm{liter})$ and during hyperinsulinemia ( $5.1 \pm 0.1$ vs $4.8 \pm 0.1 \mathrm{mmol} /$ liter $)$. The fasting serum insulin concentration in the hypertensives $(49 \pm 12)$ was slightly but not significantly higher than in the normal subjects ( $34 \pm 6 \mathrm{pmol} /$ liter). During hyperinsulinemia, serum insulin concentrations were similar in the two groups ( $418 \pm 24$ vs $394 \pm 23 \mathrm{pmol} /$ liter, respectively).

Fasting plasma FFA concentrations were higher in the hypertensive than the normal subjects in the basal state $(829 \pm 59$ vs $544 \pm 51 \mu \mathrm{mol} /$ liter $P<0.001$ ) and during hyperinsulinemia $(139 \pm 8$ vs $96 \pm 9 \mu \mathrm{mol} / \mathrm{liter}, P<0.01)$. The increased FFA concentrations in the face of comparable insulin concentrations suggest insulin resistance of antilipolysis in the hypertensives.

Whole body and skeletal muscle glucose uptake. The hypertensive subjects were insulin resistant since the rate of whole body glucose uptake was $36 \%$ lower than in the normal subjects ( $28 \pm 3$ vs $44 \pm 3 \mu \mathrm{mol} / \mathrm{kg}$ per min, respectively, $P<0.01$ ).

When individual PET derived images of ${ }^{18}$ FDG uptake rates were scaled to the same $\mathrm{nCi} /$ pixel level, ${ }^{18} \mathrm{FDG}$ uptake was decreased in femoral muscles in the hypertensives subjects (Fig. 3 ). Femoral muscle glucose uptake averaged $64 \pm 11 \mu \mathrm{mol} / \mathrm{kg}$ per $\min$ in the hypertensive subjects which was $32 \%$ lower than in the normal subjects $(94 \pm 8 \mu \mathrm{mol} / \mathrm{kg}$ per $\mathrm{min}, P<0.05$, Fig. $4)$. There was a positive correlation between femoral muscle and whole body glucose uptake both in the hypertensives $(r$ $=0.89, P<0.001)$ and the normal subjects $(r=0.84, P$ $<0.001$, Fig. 5).

Myocardial glucose uptake. When individual PET derived images of ${ }^{18} \mathrm{FDG}$ uptake rates were scaled to the same $\mathrm{nCi} /$ pixel level, ${ }^{18}$ FDG uptake was increased in the heart of the hypertensive subjects compared to the normal subjects (Fig. 3). The actual rate of glucose uptake was $33 \%$ higher in the heart of hypertensives $(939 \pm 51)$ than the normal subjects $(707 \pm 46$ 

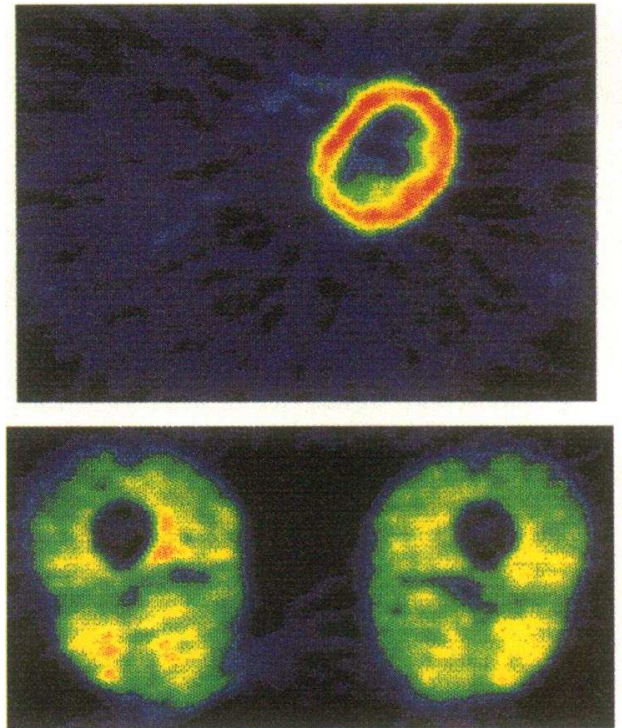

HYPERTENSIVE
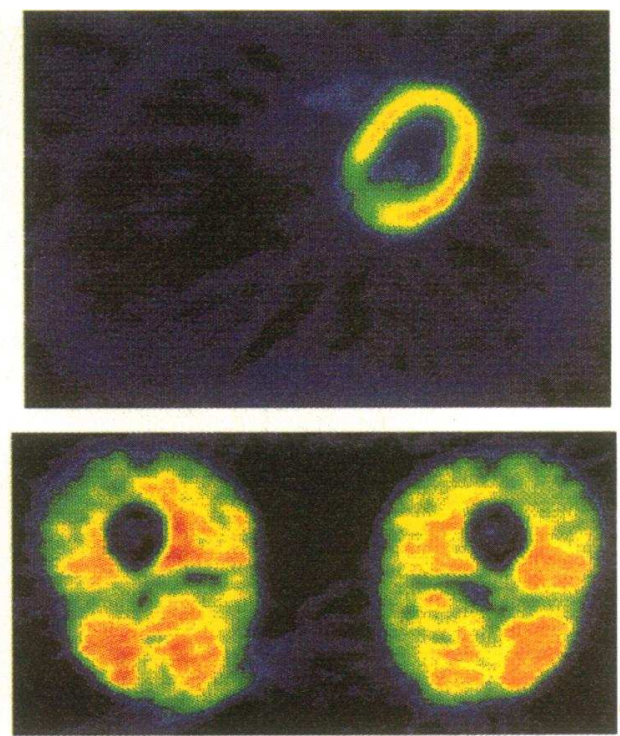

CONTROL
Figure 3. Examples of ${ }^{18} \mathrm{FDG}$ images scaled to the same nanocurie per pixel level of the heart (top) and femoral regions (bottom) as determined with positron emission tomography in a hypertensive and a normotensive subject. $\mu \mathrm{mol} / \mathrm{kg}$ heart muscle per min, $P<0.005$, Fig. 4$)$. In the hypertensive subjects, the left ventricular mass was similar to that in the normal subjects (Table I). The ejection fractions were also comparable between the hypertensive and the normal subjects (Table I).

Systolic and diastolic blood pressures, the rate pressure product and myocardial minute work per left ventricular mass, and minute work indexes during the insulin clamp were greater in the hypertensive than the normal subjects (Table I). Heart glucose uptake was correlated with systolic blood pressure $(r$ $=0.66, P<0.001$, Fig. 6$)$, the rate pressure product $(r=0.62$, $P<0.002)$, minute work per myocardial mass $(r=0.48, P$ $<0.05)$, and the minute work index $(r=0.48, P<0.05)$.

Heart glucose uptake per muscle mass was $20 \pm 4$-fold greater than femoral muscle glucose uptake in the hypertensive subjects, while the corresponding ratio in the normal subjects was $8 \pm 1(P<0.05)$. The heart utilized $7.9 \pm 0.9 \%$ of whole body glucose uptake in the hypertensives and $4.3 \pm 0.6 \%$ in the normal subjects. When the individual segments of the heart were analyzed, glucose uptake was uniformly increased in the hypertensive compared to the normal subjects (Fig. 7). Glucose
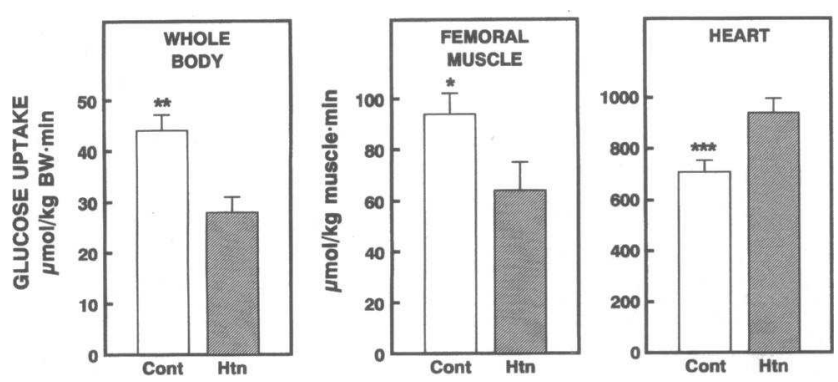

Figure 4. The rate of glucose uptake at the level of the whole body, in femoral muscles, and the heart. The values are expressed as $\mu \mathrm{mol} / \mathrm{kg}$ body weight $(B W)$ for whole body glucose uptake and as $\mu \mathrm{mol} / \mathrm{kg}$ muscle per min for skeletal and heart muscles. Open bars denote control (Cont) and solid bars hypertensive $(\mathrm{Htn})$ subjects. ${ }^{*} P<0.05, * * P$ $<0.01, * * * P<0.001$ for hypertensives vs control subjects. uptake in the heart did not differ between the segments in hypertensives but was slightly lower in the apical than the posteroseptal, posterobasilar, and inferior segments within the group of normal subjects (Fig. 7).

Physical fitness, age, whole body, and skeletal muscle insulin sensitivity. There was no significant difference in $\mathrm{Vo}_{2 \max }$ between the hypertensive $(37 \pm 3)$ and the normal subjects $(43 \pm 2 \mathrm{ml} / \mathrm{kg}$ per min, Table I). The rate of whole body glucose uptake was, however, positively correlated with $\mathrm{Vo}_{2 \max }(r$ $=0.58, P<0.01$ ). When $\mathrm{Vo}_{2 \max }$ was used as the covariate, the difference in both femoral muscle and whole body glucose uptake rates between hypertensives and normal subjects virtually disappeared $(P>0.10)$. When age was used as the covariate, the difference in both femoral and whole body glucose uptake rates between the groups remained significant $(r<0.05$ for both).

\section{Discussion}

As in previous studies (2), we found insulin resistance of glucose uptake at the level of the whole body in patients with essential hypertension. When quantitated directly in muscle tissue, this decrease was attributable to a decrease in glucose uptake in skeletal muscles. In contrast to the $30 \%$ decrease in

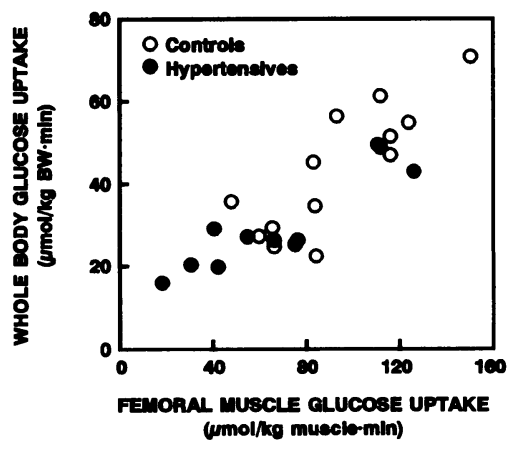

Figure 5. The relationship between femoral muscle glucose uptake as determined with PET and whole body glucose uptake as determined by the euglycemic insulin clamp technique. BW, body weight. 


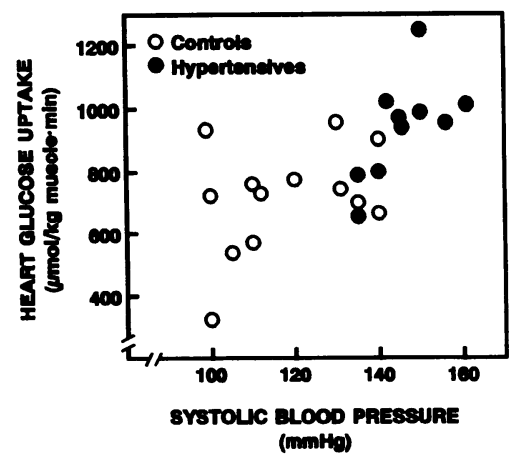

Figure 6. The relationship between systolic blood pressure and heart glucose uptake.

glucose uptake in skeletal muscle, insulin stimulated glucose uptake was $30 \%$ increased in the myocardium. The increase in myocardial glucose uptake in the hypertensives was observed despite similar left ventricular masses in the two groups. The normal size of the left ventricle is compatible with the mild hypertension characterizing the present study subjects and suggests a relatively short period or mild severity of pressure overload.

Regarding the mechanisms of the increased heart glucose uptake, both a shift in fuel utilization, and a change in cardiac work should be considered. The heart is able to derive energy from a variety of sources including glucose, FFA, lactate, amino acids, and ketone bodies (28). Postprandially and during brief fasting, glucose and FFA are the predominant fuels. In humans, the serum FFA concentrations and the arterial-coronary sinus glucose differences (29) and glucose uptake (7) are closely and inversely correlated after an overnight fast. Since serum FFA concentrations were higher both basally and during hyperinsulinemia in the hypertensive than the normal subjects, diminished FFA utilization is unlikely to explain the increase in heart glucose uptake. This implies that factors other than a shift in fuel preference was responsible for the increased heart glucose uptake in the hypertensives.

Systolic blood pressure and rate pressure product, and minute work per heart mass and body surface area were all higher in the hypertensives than the control subjects, suggesting an increased need of energy per contractile unit. Heart glucose uptake was also correlated with systolic blood pressure and the rate pressure product and minute work. In animal studies, immediately after a rise in myocardial tension, myocardial oxygen consumption and thus energy production in the myocardium increased in proportion to the increase in tension $(8,9)$. In humans, cardiac hyperfunction induced by acute exercise (8) and atrial pacing (9) is accompanied by considerable augmentation of myocardial oxygen consumption per unit mass of myocardium. During incremental atrial pacing after an overnight fast, both oxygen consumption and glucose uptake rise linearly (9). In perfused hearts of normal rats, acutely increasing cardiac work by raising the perfusion pressure also induces parallel increases in oxygen consumption and glucose in the absence of insulin (30). The present finding of an increase in glucose consumption per unit heart mass, which was proportional to estimated cardiac work is therefore compatible with the idea that the increase in glucose utilization reflected an increase in oxygen consumption.

The present data are unlikely to be applicable to patients with long-standing hypertension and left ventricular hypertrophy. In such patients, myocardial oxygen consumption and energy production per unit mass of myocardium are usually normal (8), although cardiac work load is increased. This apparent paradox seems to be explained by distribution of myocardial function throughout an increased mass. Thus, we interpret the increased glucose uptake in patients with mild essential hypertension and a normal left ventricular mass to represent an early event which precedes the development of left ventricular hypertrophy. In rats, the increase in myocardial mass and accompanying decrease in oxygen consumption per unit heart mass towards normal, which is characteristic for the development of left ventricular hypertrophy, is associated with a shift in myosin isoenzymes from a faster $\left(V_{1}\right)$ to a slower $\left(V_{3}\right)$ enzymatic form, a decrease in adenosinetriphosphatase activity, and increase in connective tissue and a decrease in myocardial contractility (8, 31-33). Oxygen consumption of working hearts decreases upon increasing $V_{3}$ expression (34). These changes may reflect an attempt of the myocardium to restore oxygen consumption and energy production towards normal.

Although glucose uptake per heart mass was increased during hyperinsulinemia in the hypertensives, this finding does not necessarily exclude the existence of insulin resistance in heart muscle. As suggested by Lillioja and Bogardus (35), perhaps

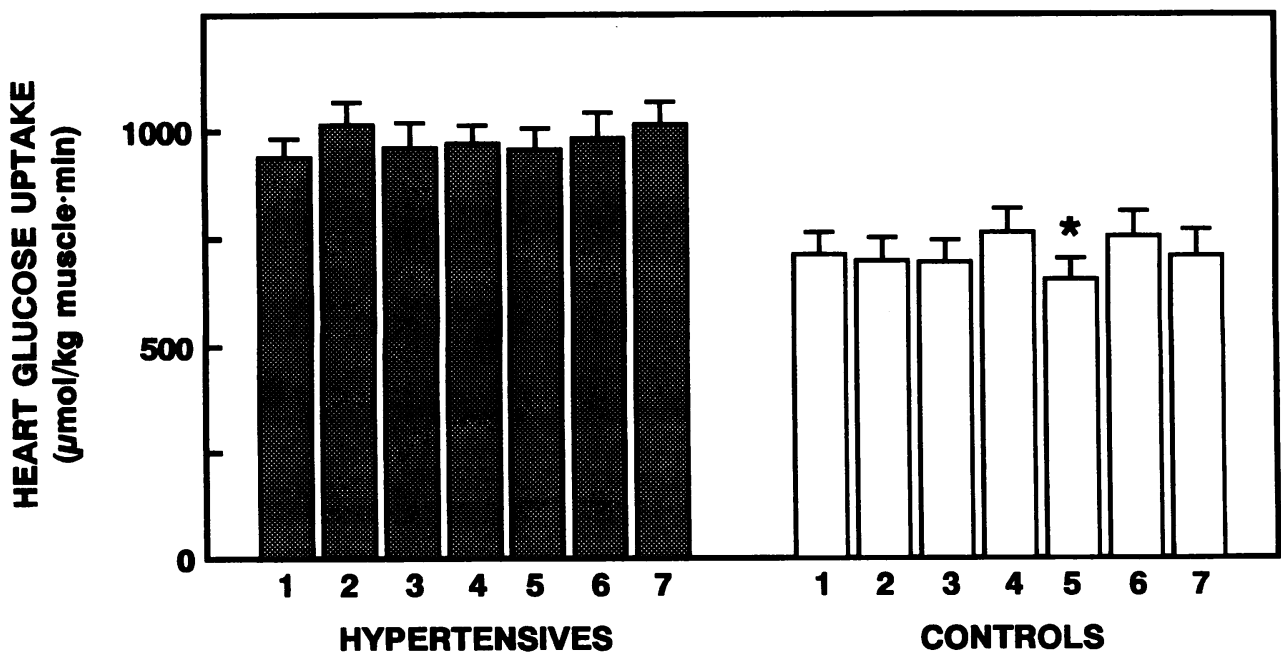

Figure 7. Comparison of heart glucose uptake rates between myocardial segments between patients with hypertension and the normal subjects in different myocardial segments. Glucose uptake was higher in every segment in the hypertensives than the normal subjects $(P<0.05$ or less $)$. $* P$ $<0.05$ segment 5 vs segments 4 , 6 , and 7. 1, anteroseptal; 2 , anterior; 3 , lateral; 4 , posteroseptal; 5 , apical; 6 , posterobasilar; 7 , inferior segment of the myocardium. 
most accurate way to normalize metabolic data is to relate substrate utilization rates to the basal metabolic rate of a tissue. As we did not measure energy expenditure directly in the present study, we cannot compare insulin-stimulated glucose uptake rates adjusted for oxygen consumption between hypertensives and normal subjects. However, heart glucose uptake and the rate pressure product, a crude measure of cardiac work as well as systolic blood pressure, were linearly correlated and seemed to fall on the same regression line in both groups (Fig. 6). This suggests that glucose uptake was not diminished in the hypertensives even if it had been related to cardiac work, and presumably oxygen consumption. Thus, the hypertensive heart muscle seems neither insulin resistant nor abnormally sensitive to insulin. This finding resembles that found in previous studies in type 1 diabetic patients in which skeletal muscle insulin resistance was not associated with insulin resistance in the heart (36). The reason for these divergent responses of skeletal and heart muscles is unknown but could be related to inherent differences in glucose metabolism between the two tissues. For example, glucose transport is rate limiting in skeletal muscle under euglycemic-hyperinsulinemic conditions (37) in contrast to glucose phosphorylation which limits glucose utilization in the heart $(38,39)$.

In patients with hypertrophic cardiomyopathy, in which the septum is thicker than the lateral wall, a relative decrease in septal flow, and glucose and free fatty acid uptake has been shown by PET (40). We did not detect differences in glucose uptake rates between anatomical regions in hypertensives who had no myocardial hypertrophy (Fig. 7). Yonekura et al. (10) found accelerated ${ }^{14} \mathrm{C}$-deoxy-glucose uptake and decreased fatty acid $\left({ }^{14} \mathrm{C}\right.$-beta-methyl heptadecanoid acid) extraction in severely hypertensive rats. These changes were localized to the subendocardial layer of the left ventricular wall in salt-sensitive hypertensive rats, while in the study of Kagaya et al. ${ }^{14} \mathrm{C}$-deoxyglucose uptake was similar between the inner and outer halves of the left ventricular wall (41). Our technique does not allow quantitation of glucose uptake in different layers of the myocardium (Fig. 3).

For glucose uptake calculations we assumed a lumped constant (LC) of 0.67 for the heart and 1.0 for skeletal muscle in both hypertensives and control subjects. The validity of 1.0 as the lumped constant for skeletal muscle is supported by our previous finding of similar glucose uptake rates measured with ${ }^{18}$ FDG and PET and the forearm balance technique under conditions identical to those of the present study (6). Also, the close correlation between whole body glucose uptake, measured simultaneously but independently of PET methodology with the insulin clamp technique, and femoral glucose uptake, measured with PET, supports the validity of the method (Fig. 5). A LC of 0.67 is commonly used for the heart $(23,24)$. Previous studies have shown that neither changes in the nutritional state nor those in work load affect the LC for heart (42).

Previous studies have documented skeletal muscle insulin sensitivity to be highly correlated with $\mathrm{VO}_{2 \max }$ and to increase by physical training (43). In endurance-trained athletes, the number of capillaries per fiber is increased (44) as is the percent type 1 , insulin-sensitive fibers $(45,46)$. In hypertensives, opposite alterations in muscle fiber type distribution and the number of capillaries per fiber have been described (47). Such changes in muscle histology might explain the lower $\mathrm{Vo}_{2 \max }$ and insulin sensitivity in the hypertensive than the normal subjects. However, in a cross-sectional analysis, it is not possible to determine whether poor physical fitness causes insulin resistance in hypertension or vice versa, or whether the correlation between $\mathrm{Vo}_{2 \max }$ is merely coincidental.

In conclusion, the present data demonstrate that insulin resistance in patients with mild untreated essential hypertension is localized to skeletal muscle. In these patients without cardiac hypertrophy, myocardial glucose uptake is increased. It may reflect increased myocardial oxygen consumption and be an early signal for the development of left ventricular hypertrophy.

\section{Acknowledgments}

We thank the technicians at the Turku University Cyclotron/PET Center for their skill and dedication throughout this study. We also thank Jukka Kapanen, M. Sci. and the Paavo Nurmi Center for the $\mathrm{Vo}_{2 \max }$ determinations.

This study was supported by the grants of the Finnish Academy of Science (H. Yki-Järvinen, P. Nuutila), Nordisk Insulinfonds Komite (H. Yki-Järvinen, P. Nuutila), and Turku University Foundation (P. Nuutila).

\section{References}

1. Modan, M., H. Halkin, S. Almog, A. Lusky, A. Eshkol, M. Shefi, A. Chetrit and Z. Fuchs. 1985. Hyperinsulinemia: a link between hypertension, obesity and glucose intolerance. J. Clin. Invest. 75:809-817.

2. Ferrannini, E., G. Buzzigoli, R. Bonadonna, M. A. Giorico, M. Oleggini, L. Graziadei, R. Pedrinelli, L. Brandi, and S. Bevilacqua. 1987. Insulin resistance in essential hypertension. N. Engl. J. Med. 317:350-357.

3. Pollare, T., H. Lithell, and C. Berne. 1990. Insulin resistance is characteristic feature of primary hypertension independent of obesity. Metab. Clin. Exp. 39:167174.

4. DeFronzo, R. A., E. Jacot, E. Jequier, E. Maeder, J. Wahren, and J. P. Felber. 1981. The effect of insulin on the disposal of intravenous glucose. Results from indirect calorimetry and hepatic and femoral venous catheterization. Diabetes. 30:1000-1007.

5. Natali, N., D. Santoro, C. Palombo, M. Cerri, S. Ghione, and E. Ferrannini. 1991. Impaired insulin action on skeletal muscle metabolism in essential hypertension. Hypertension (Dallas). 17:170-178.

6. Nuutila, P., V. A. Koivisto, J. Knuuti, U. Ruotsalainen, M. Teräs, M Haaparanta, J. Bergman, O. Solin, L.-M. Voipio-Pulkki, U. Wegelius, and H. Yki-Järvinen. 1992. Glucose-free fatty acid cycle operates in human heart and skeletal muscle in vivo. J. Clin. Invest. 89:1767-1744.

7. Nuutila, P., M. J. Knuuti, U. Ruotsalainen, M. Teräs, L.-M. Voipio-Pulkki, M. Haaparanta, O. Solin, U. Wegelius, and H. Yki-Järvinen. 1994. Effect of antilipolysis on heart and skeletal muscle glucose uptake in overnight fasted humans. Am. J. Physiol. 267:E941-E946.

8. Meerson, F. Z. 1969. Transformation of energy in the myocardium in hyperfunction, hypertrophy, and heart failure. Circ. Res. 25(Suppl. II):II-55-II81.

9. Camici, P. P. Marraccini, M. Marzilli, R. Lorenzoni, G. Buzzigoli, R. Puntoni, C. Boni, C. R. Bellina, G. A. Klassen, A. L'Abbate, and E. Ferrannini. 1989. Coronary hemodynamics and myocardial metabolism during and after pacing in normal humans. Am. J. Physiol. 257:E309-E317.

10. Yonekura, Y., A. B. Brill, P. Som, K. Yamamoto, S. C. Srivastava, J. Iwai, D. R. Elmalch, E. Livini, H. W. Strauss, M. M. Goodman, and F. F. Knapp, Jr. 1985. Regional myocardial substrate uptake in hypertensive rats: a quantitative autoradiographic measurement. Science (Wash. DC). 227:1494-1496.

11. Frohlich, E. D. 1989. Heart Failure hypertrophy, cardiac diseases and hypertension: recent experiences. J. Am. Coll. Cardiol. 14:1587-1594.

12. DeFronzo, R. A., J. D. Tobin, and R. Andres. 1979. The glucose clamp technique: a method for quantifying insulin secretion and resistance. Am. J. Physiol. 237:E214-E223.

13. Kadish, A. H., R. L. Little, and J. C. Sternberg. 1968. A new and rapid method for the determination of glucose by measurement of rate oxygen consumption. Clin. Chem. 14:116-131.

14. Yki-Järvinen, H., A. Consoli, N. Nurjhan, A. A. Young, and J. E. Gerich 1989. Mechanism for underestimation of isotopically determined glucose disposal. Diabetes. 38:744-751

15. Kuzuya, H., P. M. Blix, D. L. Horwitz, D. F. Steiner, and A. Rubenstein. 1977. Determination of free and total insulin and C-peptide in insulin-treated diabetics. Diabetes. 26:22-29.

16. Miles, J., R. Glasscock, J. Aikens, J. Gerich, and M. Haymond. 1983. A 
microfluorometric method for the determination of free fatty acids in plasma. $J$. Lipid Res. 24:96-99.

17. Hamacher, K., H. H. Coenen, and G. Stöcklin. 1986. Efficient stereospecific synthesis of no-carrier-added 2 - $\left[{ }^{18} \mathrm{~F}\right]$-fluoro-2-deoxy-D-glucose using aminopolyether supported nucleophilic substitution. J. Nucl. Med. 27:235-238.

18. Spinks, T. J., R. Guzzardi, and C. R. Bellina. 1988. Performance characteristics of a whole-body position tomograph. J. Nucl. Med. 29:1833-1841.

19. Knuuti, J., P. Nuutila, U. Ruotsalainen, M. Saraste, R. Härkönen, A. Ahonen, J. Hartiala, M. Teräs, M. Haaparanta, U. Wegelius, et al. 1992. Euglycemic hyperinsulinemic clamp and oral glucose load in stimulating myocardial glucose utilization during positron emission tomography. J. Nucl. Med. 33:12551262.

20. Schelbert, H. R., E. Henze, H. R. Shon, R. Keen, H. Hansen, C. Selin, S.-C. Huang, J. R. Barrio, and M. Phelps. 1983. C-11 palmitate for the noninvasive evaluation of regional myocardial fatty acid metabolism with positron computed tomography. III. In vivo demonstration of the effects of substrate availability on myocardial metabolism. Am. Heart J. 105:492-504.

21. Huang, S.-C., M. Phelps, E. Hoffman, K. Sideris, C. Selin, and D. Kuhl. 1980. Noninvasive determination of local cerebral metabolic rate of glucose in man. Am. J. Physiol. 238:E69-E82.

22. Patlak, C. S., and R. G. Blasberg. 1985. Graphical evaluation of bloodto-brain transfer constants from multiple-time uptake data. Generalizations, $J$. Cereb. Blood Flow Metab. 5:584-590.

23. Ratib, O., M. E. Phelps, S.-C. Huang, E. Henze, C. E. Selin, and C. E. Schelout. 1982. The deoxyglucose method for the estimation of basal myocardial glucose metabolism with positron computed tomography. J. Nucl. Med. 23:577586.

24. Choi, Y., R. A. Hawkins, S.-C. Huang, S. S. Gambhir, R. C. Brunken, M. E. Phelps, and H. R. Schelbert. 1991. Parametric images of myocardial metabolic rate of glucose generated from dynamic cardiac PET and $2-\left({ }^{18} \mathrm{~F}\right)$ fluoro-2deoxy-d-glucose studies. J. Nucl. Med. 32:733-738.

25. Mossberg, K. A., R. W. Rowe, T. J. Tewson, and H. Taegtmeyer. 1989. Rabbit hindlimb glucose uptake assessed with positron-emitting fluorodeoxyglucose. J. Appl. Physiol. 67:1569-1577.

26. Devereux, R. B., and N. Reichek. 1977. Echocardiographic determination of left ventricular mass in man. Anatomical validation of the method. Circulation. 55:613-618.

27. Opie, L. H. 1991. Myocardial oxygen uptake. In The Heart, Physiology and Metabolism. L. H. Opie, editor. Raven Press, Ltd., New York. 339-368.

28. Opie, L. H. 1991. Fuels: carbohydrates and lipids. In The Heart, Physiology and Metabolism. L. H. Opie, editor. Raven Press, Ltd., New York. 208-246.

29. Lassers, B. W., L. Kaijser, and L. A. Carlson. 1972. Myocardial lipid and carbohydrate metabolism in healthy, fasting men at rest: studies during continuous infusion of ${ }^{13} \mathrm{H}$-palmitate. Eur. J. Clin. Invest. 2:348-358.

30. Zaninetti, D., R. Greco-Perotto, and B. Jeanrenaud. 1988. Heart glucose transport and transporters in rat heart: regulation by insulin, workload and glucose. Diabetologia. 31:108-113.

31. Izumo, S., A.-M. Lompré, R. Matsuoka, G. Koren, K. Schwartz, B. NadalGinard, and V. Mahdavi. 1987. Myosin heavy chain messenger RNA and protein isoform transitions during cardiac hypertrophy. J. Clin. Invest. 79:970-977.
32. Anversa, P., P. Li, A. Malhotra, X. Zhang, M. V. Herman, and J. M. Capasso. 1993. Effects of hypertension and coronary constriction on cardiac function, morphology, and contractile proteins in rats. Am. J. Physiol. 265:H713H724.

33. Pearlman, E. S., K. T. Weber, J. S. Janicki, G. G. Pietra, and A. P. Fishman. 1982. Muscle fiber orientation and connective tissue content in the hypertrophied human heart. Lab. Invest. 46:158-164.

34. Kissling, G., H. Rupp, L. Malloy, and R. Jacob. 1982. Alterations in cardiac oxygen consumption under chronic pressure overload. Significance of the isoenzyme pattern of myosin. Basic Res. Cardiol. 77:255-269.

35. Lillioja, S., and C. Bogardus. 1988. Obesity and insulin resistance: lessons learned from the Pima Indians. Diabetes Metab. Rev. 4:517-540.

36. Nuutila, P., J. Knuuti, U. Ruotsalainen, V. A. Koivisto, E. Eronen, M. Teräs, J. Bergman, M. Haaparanta, L.-M. Voipio-Pulkki, J. Viikari, et al. 1993. Insulin resistance is localized to skeletal but not heart muscle in type 1 diabetes. Am. J. Physiol. 264:E756-E762.

37. Katz, A., B. L. Nyomba, and C. Bogardus. 1988. No accumulation of glucose in human skeletal muscle during euglycemic hyperinsulinemia. Am. $J$. Physiol. 255:E942-E945.

38. Morgan, H. E., M. J. Henderson, D. M. Regen, and C. R. Park. 1961. Regulation of glucose uptake in muscle. J. Biol. Chem. 236:253-261.

39. Manchester, J., X. Kong, J. Nerbonne, O. H. Lowry, and J. C. Lawrence, Jr. 1994. Glucose transport and phosphorylation in single cardiac myocytes: ratelimiting steps in glucose metabolism. Am. J. Physiol. 29:E326-E333.

40. Grover-McKay, M., M. Schwaiger, J. Krivokapich, J. K. Perloff, M. E. Phelps, and H. R. Schelbert. 1989. Regional myocardial blood flow and metabolism at rest in mildly symptomatic patients with hypertrophic cardiomyopathy. $J$. Am. Coll. Cardiol. 13:317-324.

41. Kagaya, Y., Y. Kanno, D. Takeyama, N. Ishide, Y. Maruyama, T. Takahashi, T. Ido, and T. Takishima. 1990. Effects of long-term pressure overload on regional myocardial glucose and free fatty acid uptake in rats. A quantitative autoradiographic study. Circulation. 81:1353-1361.

42. Krivokapich, J., S. C. Huang, C. E. Selin, and M. E. Phelps ME. 1987. Fluorodeoxyglucose rate constants, lumped constant, and glucose metabolic rate in rabbit heart. Am. J. Physiol. 252:H777-H787.

43. Koivisto, V. A., H. Yki-Järvinen, and R. A. DeFronzo. 1986. Physical training and insulin sensitivity. Diabetes Metab. Rev. 1:445-481.

44. Andersen, P., and J. Henriksson. 1977. Capillary supply of the quadriceps femoris muscle of man: adaptive response to exercise. J. Physiol. 270:677-690.

45. Gollnick, P. D., R. B. Armstrong, I. V. C. W. Saubert, K. Piehl, and B. Saltin. 1972. Enzyme activity and fiber composition in skeletal muscle of untrained and trained men. J. Appl. Physiol. 33:312-319.

46. Lillioja S., A. A. Young, C. L. Cutler, J. L. Ivy, W. G. H. Abbott, J. K. Zawadzki, H. Yki-Järvinen, L. Christin, T. W. Secomb, and C. Bogardus. 1987. Skeletal muscle capillary density and fiber type are possible determinants of in vivo insulin resistance in man. J. Clin. Invest. 80:415-424.

47. Juhlin-Dannfelt, A., M. Frisk-Homberg, J. Karlsson, and P. Tesch. 1979. Central and peripheral circulation in relation to muscle-fbre composition in normoand hypertensive man. Clin. Sci. 56:335-340. 